\title{
Energy dissipation of rockfalls by coppice structures
}

\author{
G. Ciabocco ${ }^{1}$, L. Boccia ${ }^{2}$, and M. N. Ripa ${ }^{1}$ \\ ${ }^{1}$ Department of technology and engineering and environment sciences and the Forest of Tuscia University, Viterbo, Italy \\ ${ }^{2}$ Department of agricultural engineering and territory - University of Naples Federico II, Italy
}

Received: 2 March 2009 - Revised: 15 June 2009 - Accepted: 16 June 2009 - Published: 26 June 2009

\begin{abstract}
The objective of this work is to develop elements to improve understanding of the behaviour of a coppice in relation to the phenomenon of falling boulders. The first section proposes an amendment to the equation for calculating the index which describes the probability of impact between a rock and plants in managed coppice forests. A study was carried out, using models to calculate the kinetic energy of a falling boulder along a slope considering the kinetic energy dissipated during the impact with the structure of forest plants managed by coppice. The output of the simulation models were then compared with the real dynamics of falling boulders in field tests using digital video.

It emerged from an analysis of the results of this comparison that a modification to the 1989 Gsteiger equation was required, in order to calculate the "Average Distance between Contacts" (ADC). To this purpose, the concept of "Structure of Interception", proposed in this paper, was developed, valid as a first approach for describing the differences in the spatial distribution of stems between coppice and forest. This study also aims to provide suggestions for forestry management, in order to maintain or increase the protective capacity of a coppice managed with conventional techniques for the area studied, modifying the dendrometric characteristics.
\end{abstract}

\section{Introduction}

Forests play an undeniably important role in mitigating the risk of rockfall, even though it is difficult to quantify this role, as forests often absorb the smaller fallen boulders. (Leibundgut et al., 1986; Lafortune et al., 1997; Hétu and Gray, 2000; Stoffel et al., 2006).

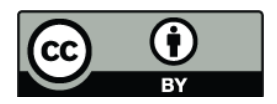

Correspondence to: G. Ciabocco (ciabocco.giovanni@gruppociabocco.it)
Italian legislation has officially recognised this role since 1923 (Royal Decree Law num. 3267 - 30.12.1923).

However, although much of the Italian territory is characterised by geomorphologic features that are very precarious in nature, it is also densely populated and rich in infrastructures. Therefore, continuous maintenance and protection of the infrastructures is required, generating high costs, technical difficulties and possible penal responsibilities for the technicians involved in the management of mountain regions.

These costs are often unsustainable and therefore, there is a great need for research into methodologies to improve the cost/benefit ratio of invested funds. To overcome deterministic factors (e.g., concepts of vulnerability, hazard and risk), it is imperative to quantify the contribution of forests in mitigating the likelihood of damage.

With regard to rockfalls, forest management models should take the multifunctional role of forests into consideration, and in particular, their role in mitigating risks from fallen boulders.

Moreover, planners and foresters should take into account the natural protective function of forests when defining measures to protect forests from rockfall events and optimize forest planning.

On a practical level, foresters can optimise the natural protective function of forests by applying target values to structure parameters such as tree density, tree spatial distribution, species composition, tree conditions, diameter distribution and the basal area. (Chauvin et al., 1994 ; Wasser and Frehner, 1996; Frehner et al., 2005; Stoffel et al., 2006) However, the development of technical specifications is required for coppice structures.

Four different phenomena have been identified in the physical effect of forest structures on the dynamics of fallen boulders: (a) kinetic energy absorption through direct impact between a boulder and a trunk, Gsteiger (1989), Zinggeler (1989), Stokes et al. (2005), Brauner (2005), Dorren et al. (2005, 2006), Lundström et al. (2007, 2009), (b)

Published by Copernicus Publications on behalf of the European Geosciences Union. 
kinetic energy absorption through interaction between a rock and shrub vegetation, (c) increasing rugosity of slope and a consequent reduction of coefficient restitution, Jones et al. (2000), (d) the positive effect of forest vegetation on geotechnical soil characteristics, Pfeiffer (1989).

The theoretical energy dissipated by forest structures depends on the number of tree/boulder impacts and on the kinetic energy dissipated by a single impact. Gsteiger (1989) proposed an index to describe the number of tree/boulder impacts in a given forest structure. This index is defined as the "Average Distance between Contacts" (ADC). Since the ADC index describes the average distance between two impacts, if the distance travelled inside the forest structure by a given boulder is known, then the hypothetical number of impacts can be estimated. In the ADC index, a random distribution of trees in the examined area is assumed, using the number of trees per hectare.

More recently, Brauner et al. (2005) and Dorren et al. (2007) resumed that in a tree/boulder impact, the tree dissipates the boulder's energy through the rotation and shifting of parts of the root system, the deformation and oscillation of the tree stem, and local penetration of the rock at the point of impact.

Dorren et al. (2007) summarised as follows the methods proposed in the literature to quantify energy absorption during tree/boulder impact: (a) Couvreur (1982) and Zinggeler (1989), this method derives the fracture energy from standard dynamics tests on a small sample; (b) Stokes et al. (2005), this method is based on static winching experiments that calculate the energy required to cause a failure in the root system, (c) Brauner et al. (2005), this method assumes that the banding energy is fully dissipated by the work expended to bend the tree stem to the point at which it breaks, (d) Dorren et al. (2006), derived the tree/boulder energy absorption capacity through real-size rockfall experiments on living trees, by measuring energy absorption as a function of tree diameter at breast height (DBH) and of rockfall impact eccentricity, (e) Lundström et al. (2007, 2009), derived the energy absorption of trees subject to rockfall and root system anchorage mechanics, for many Alpine Conifer species, with a new approach and an experimental method, (f) Jonsson (2007), used full-scale impact test data to calibrating a numerical single tree impact model, using Finite Element Method (FEM), in this way the author can consider energy absorption of tree dependent on: $\mathrm{DBH}$, tree/boulder impact height, angle and eccentricity, level of tree damage and material properties.

Many of these studies were predominantly conducted in the Alpine area using characteristic tree species, Berger et al. (2001, 2004), Dorren et al. (2004, 2005, 2006), Brauner et al. (2005), Stokes et al. (2005), Lundström et al. (2007, 2009). Through these studies, numerous important steps have been made towards understanding the mitigation of rockfall risks. They have enabled a shift from a descrip- tive approach to silvicultural systems to a more pragmatic method.

With reference to fallen boulders, the behaviour of coppice is very different from that of high forest, depending on the probability of tree/boulder impacts, and the energy dissipation per impact. Since the spatial distribution of plants differs, the same approach cannot be employed to determine the probability of an impact. Moreover, the effect of an impact upon the group of stump shoots of a coppiced tree is not necessarily the same as that of a similar impact on a noncoppiced plant of equivalent section.

The aim of this research was to make an initial contribution to estimating the energy absorbed by a coppice. In particular, it is focused on evaluating the energy dissipated by a specific Appennine forest structure, by comparing the kinetic energy dissipation calculated by means of equations proposed in the literature with the actual energy measured in a full-scale test, in order to adapt the ADC index equation.

Assuming that the spatial distribution of trees in a coppice differs from that of high forest, a modification to the original equation published by Gsteiger (1989) to calculate the ADC index is proposed, introducing what the authors term the "Structure of Interception".

Considering the absence of specific studies on the mechanical behaviour of tree stems in a coppice subject to rockfall events, a simplified approach was adopted to determining the kinetic energy absorption per impact. Recent studies (Dorren et al., 2006, Lundström et al., 2007, 2009) have made considerable progress towards understanding the mechanism of kinetic energy absorption during tree/boulder impact, through real-size tests. However, the results of these studies are not easily applicable to coppices, due to the differences in structure between the trees in a coppice and those in high forest areas (e.g., size of stems, root system/stem ratio, type of wood).

This study also aimed to modify the equation for calculating the number of impacts using the ADC index proposed by Gsteiger (1989), and to investigate the possibility of providing forest managers with some parameters and technical aids in order to increase the protective function of Appennine coppice against falling rocks by optimizing traditional forestry management techniques.

\section{Materials and method}

The experimental site is located in central Italy $\left(42^{\circ} 56^{\prime} 14^{\prime \prime} \mathrm{N}\right.$, $13^{\circ} 07^{\prime} 03^{\prime \prime} \mathrm{E}$ ), $700 \mathrm{~m}$ above mean sea level (a.m.s.l.); the rocks are characterised by a compact lithology of limestone, while the forests are predominantly of flowering ash (Fraxinus ornus) and hop hornbeam (Ostrya carpinifolia) forest, once managed with a simple coppice system, but now entirely abandoned. The dendrometric data characterising the forest area studied in this work are reported in Table 1. 
Table 1. Data acquired in two forest sample plots. The data are input to calculate the average distance between contacts with Gsteiger 1989 equation and with modified equation. The two forestry sampling characterize the real structure forest crossed by analyzed boulders.

\begin{tabular}{|c|c|c|}
\hline Parameter & ADS_1 & ADS_2 \\
\hline Geographic sample area $\left(\mathrm{m}^{2}\right)$ & 400 & 400 \\
\hline Slope $\left({ }^{\circ}\right)$ & 40 & 34 \\
\hline Topographic sample area $\left(\mathrm{m}^{2}\right)$ & 306 & 332 \\
\hline Forest type & flowering ash and hop hornbeam forest & flowering ash and hop hornbeam forest \\
\hline Silvicultural system & simple coppice system & young degradation forest \\
\hline Metres Above Sea Level (m) & 709 & 683 \\
\hline Exposure & SE & SE \\
\hline Skeletal (\%) & 60 & 90 \\
\hline Fragmental $(\%)$ & 3 & 0 \\
\hline Basal area $\left(\mathrm{m}^{2}\right)$ & 25.929 & 8.11 \\
\hline Mean basal area $\left(\mathrm{m}^{2}\right)$ & 0.0029 & 0.0017 \\
\hline Mean diameter $(\mathrm{m})$ & 0.061 & 0.047 \\
\hline Stand density trees/hectare (num.) & 9076 & 4641 \\
\hline Stump/hectare (num.) & 3688 & 2807 \\
\hline$N$ of ADC (num.) Gsteiger, 1989 & 4438 & 3349 \\
\hline$A\left(\mathrm{~m}^{2}\right)$ & 10000 & 10000 \\
\hline Ns (num.) modif. Gsteiger, 1989 & 750 & 542 \\
\hline$N c$ (num.) modif. Gsteiger, 1989 & 3688 & 2807 \\
\hline$d b h_{m}(\mathrm{~m})$ & 0.061 & 0.047 \\
\hline$d b h_{\text {int }}(\mathrm{m})$ & 0.5 & 0.5 \\
\hline$d b h_{s i}(\mathrm{~m})$ & 0.561 & 0.547 \\
\hline$h_{m}(\mathrm{~m})$ & 6 & 4 \\
\hline$V_{m}\left(\mathrm{~m}^{3}\right)$ & 0.0107 & 0.0059 \\
\hline
\end{tabular}

The first step in producing the model was to simulate rockfall dynamics using PC-Massi software ${ }^{\complement}$ Bruschi Alberto Ver. 3.2.0, by means of which the experimental site was reproduced using the recorded data to recreate the conditions (i.e., rock mass, slope, track length and morphometric data), while considering the trajectory without forest cover. This software, concerning rockfall dynamic trajectory simulation, utilised a model based on stochastic analysis. The software was derived from calculations based on the Colorado Rockfall Simulation Program (C.R.S.P) model, developed by Pfeiffer et al. (1988, 1990, 1993). Input data and geotechnical coefficients were derived from the examination of a digital video analysis of the trajectory of fallen boulders at the experimental site, and are reported in Tables 2 and 3.

Once the boulder dynamics were known, it was possible to estimate the kinetic energy of the boulder dissipated during its track through the forest structure. The parameters used for the simulation were those of a real Apennine coppice case, reported in Table 1.

The number of impacts was calculated using Eq. (1), Gsteiger (1989), and Eq. (2) proposed in the literature. By means of Eq. (1) it is possible determine Average Distance between Contacts (ADC) index that depends on: (a) the diameter of the boulder $(B),(\mathrm{b})$ the horizontal projection of the sample area $(A),(\mathrm{c})$ the mean trunk diameter $\left(d b h_{m}\right)$ in the
Table 2. Rock geometry and material properties and some input data for rockfall dynamics simulation. The parameters were acquired in the starting zone of rockfalls, before the controlled removing, and in the deposition zone.

\begin{tabular}{lr}
\hline Parameter & \\
\hline Shape of boulder & Cylinder \\
Height of boulder $(\mathrm{m})$ & 0.8 \\
Diameter of boulder $(\mathrm{m})$ & 0.56 \\
Specific gravity of rock $\left(\mathrm{kg} / \mathrm{m}^{3}\right)$ & 2600 \\
Simulation (num.) & 999 \\
Start horizontal speed $v_{x}(\mathrm{~m} / \mathrm{s})$ & 0.3 \\
Start vertical speed $v_{y}(\mathrm{~m} / \mathrm{s})$ & -0.3 \\
Control point (horizontal distance) $(\mathrm{m})$ & 135 \\
\hline
\end{tabular}

sample area $(A),(\mathrm{d})$ the number of trees $(N)$ in the sample area $(A)$.

$\mathrm{ADC}=\frac{A}{N \cdot B+N \cdot d b h_{m}}=\frac{\mathrm{m}^{2}}{\mathrm{~m}}$

Since the ADC index describes the average distance between two impacts, if the course length $\left(L_{\text {tra }}\right)$ that is travelled by the boulder inside the forest structure is known, then the 
Table 3. Slope geometry and geotechnical properties that we have used as input data for for rockfall dynamics simulation with PCMassi $^{\circledR}$ (by Alberto Bruschi) simulation software. The data were acquired through a slope analyzed survey in real size and through Geographical Information Systems G.I.S. software.

\begin{tabular}{llllllll}
\hline Segment & $X_{i}$ & $Y_{i}$ & $X_{f}$ & $Y_{f}$ & $\mathbf{r}_{n}$ & $\mathrm{r}_{\mathrm{t}}$ & $\theta$ \\
\hline 1 & 0 & 126 & 10 & 106 & 0.31 & 0.87 & 0.25 \\
2 & 10 & 106 & 13 & 86 & 0.4 & 0.9 & 0.001 \\
3 & 13 & 86 & 26.95 & 76 & 0.31 & 0.83 & 0.15 \\
4 & 26.95 & 76 & 42.8 & 66 & 0.31 & 0.83 & 0.15 \\
5 & 42.8 & 66 & 48.11 & 61 & 0.31 & 0.83 & 0.15 \\
6 & 48.11 & 61 & 56.36 & 56 & 0.31 & 0.83 & 0.15 \\
7 & 56.36 & 56 & 70.69 & 46 & 0.31 & 0.83 & 0.15 \\
8 & 70.69 & 46 & 84.66 & 36 & 0.31 & 0.83 & 0.15 \\
9 & 84.66 & 36 & 97.43 & 26 & 0.31 & 0.83 & 0.15 \\
10 & 97.43 & 26 & 115.42 & 16 & 0.31 & 0.83 & 0.15 \\
11 & 115.42 & 16 & 134.59 & 6 & 0.31 & 0.83 & 0.15 \\
12 & 134.59 & 6 & 144.33 & 2 & 0.31 & 0.83 & 0.15 \\
13 & 144.33 & 2 & 152.68 & 0 & 0.31 & 0.83 & 0.15 \\
\hline
\end{tabular}

hypothetical number of impacts $\left(N_{i p}\right)$ can be estimated by applying Eq. (2):

$N_{i p}=\frac{L_{\text {tra }}}{\mathrm{ADC}}$

In this work, the kinetic energy dissipated by a single impact $\left(E_{\text {diss }}\right)$, was estimated adopting the approach proposed by Brauner (2005), and using Eq. (3). This approach is based on the assumption that all the kinetic energy of the boulder is required to break the trunk, taking into account the volume of the trunk itself. Therefore it can be assumed that all of the energy is dissipated virtually in the work required to reach the breaking point of the trunk $\left(W_{d b h m}\right)$ (Brauner, 2005).

Thus, the work involved in breaking the trunk concerns only the area affected by the deformation of wood fibres. In order to utilise the recorded data relative to tree size, a magnitude which represents the work involved in breaking the trunk as a unit of volume must be introduced, this is termed $U_{\mathrm{fr}-\text { Wood }}$ and is expressed in $J / m$ (Brauner, 2005). $U_{\mathrm{fr}-\text { Wood }}$ represents a relationship between the energy absorbed during impact, which produces the trunk fracture, and the volume of wood fractured the volume of the trunk. In other words, the work required to break the trunk for a given impact, or the energy dissipated $\left(W_{d b h m}\right)$ is calculated by considering the average trunk volume $\left(V_{m}\right)$, calculated using real data from forest measurements, the average diameter at breast height $\left(d b h_{m}\right)$ and the average height $\left(h_{m}\right)$ :

$W_{d b h m}=V_{m} \cdot U_{\mathrm{fr}-\mathrm{Wood}}$

In this test, the work involved in breaking the trunk per volume unit $\left(U_{\mathrm{fr}-\mathrm{Wood}}\right)$, was derived from literature data proposed by Niemz, 1993; Berger et al., 2001; Brauner 2005, reported in Table 4.

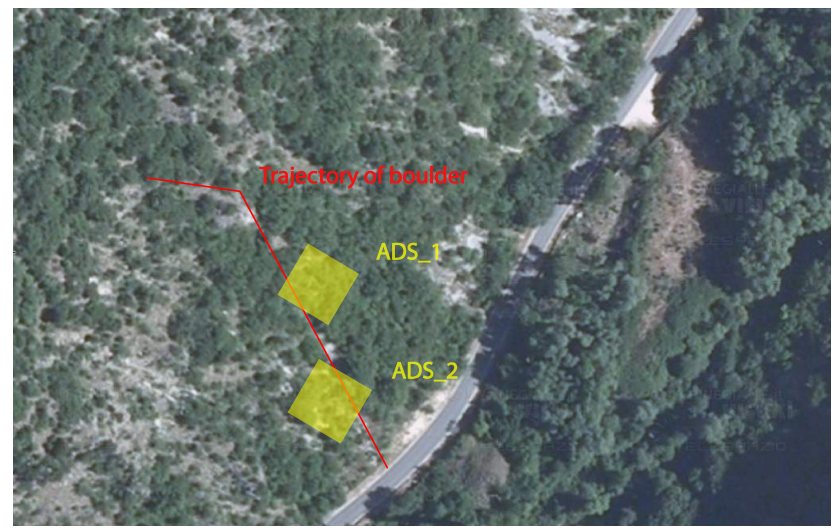

Fig. 1. Aerial photograph of forest sample plots, located in two varieties of forest structure, with trajectory of boulder highlighted.

Total dissipated kinetic energy ( $\left.E_{\text {diss }}\right)$, along course length into the forest structure, is calculated according to Eq. (4)

$E_{\text {diss }}=\frac{L_{\text {tra }}}{\mathrm{ADC}} \cdot V_{m} \cdot U_{\mathrm{fr}-\text { Wood }}=J$

To carry out the analysis, it was necessary to determine the parameters required to calculate the ADC index. Two sample plots along the trajectory of the boulder's fall were taken into consideration. The two sample plots represent the variety of typologies in forest structure crossed by the boulder, see Fig. 1 and Table 1.

The residual kinetic energy of the boulder obtained by simulation, derived from the difference between the kinetic energy and the energy dissipated by the forest (estimated from the control section), was compared to the authentic residual kinetic energy, estimated using the digital video images of the experimental tests.

The real speed of the boulder leaving the forest structure, and, therefore, its acquired kinetic energy, were determined by a digital video analysis of the experimental test, using the software AviStep (Michel Delabaere) (Version 2.1.1). This software allows the speed and acceleration of an object to be calculated through film, taking into account the camera data acquisition parameters (i.e., number of frames per second) and references in space relative to the object (i.e., a known distance). To make this analysis, we used a 10 frames video captured when the boulder, leaving the forest structure, has gone through the first $3 \mathrm{~m}$.

In examining data from the experimental video, the kinetic energy, $E_{c-\text { (real) }}$, leaving the forest after impact with the forest structure was obtained. This energy was compared with the difference between $E_{c \text {-(simulate), }}$, (the kinetic energy calculated at the same point with simulated rockfall dynamics, which was then subtracted) and $E_{\text {diss-(calculate) }}$ (the energy dissipated by the forest, using the Gsteiger approach).

$E_{C-\text { (simulate) }}-E_{\text {diss-(calculate) }}$ compare to $E_{C-\text { (real) }}$ 
Table 4. Literature data reported in Brauner 2005, that we used to calculate dissipated kinetic energy from a single impact. In this table we can see work of breaking as a unit of volume $\left(U_{\mathrm{fr}-\text { Wood }}\right)$.

\begin{tabular}{lcll}
\hline Trees species & $E_{-\bmod }\left(\mathrm{N} / \mathrm{mm}^{2}\right)$ & $\varepsilon-f r$ & $U_{\text {frWood }}\left(\mathrm{J} / \mathrm{m}^{3}\right)$ \\
\hline Conifers (Picea abies) & 5281 & 49.98 & 92213 \\
Forest broadleaves (Fagus selvatica) & 7501 & 104.00 & 102800 \\
\hline
\end{tabular}

Table 5. Average output values on boulder speed and kinetic energy carried out with dynamic simulation model of rockfalls, hypothesized without tree/boulder impacts.

\begin{tabular}{ll}
\hline Parameter & \\
\hline Speed $(\mathrm{m} / \mathrm{s})$ & 20.94 \\
Kinetic energy $(\mathrm{kj})$ & 122 \\
\hline
\end{tabular}

Using the simulation of rockfall dynamics, hypothesized without the interaction between boulder dynamics and the

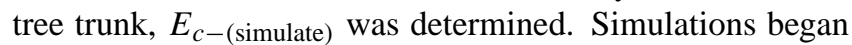
with the data input reported in Tables 1 and 2, while the average output values are reported in Table 5.

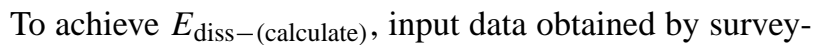
ing were used, as well as the data relative to the forest sample plots reported in Table 6. Equation (4) was applied for each different forest structure, and a value of $34 \mathrm{~kJ}$ of total energy absorption was obtained.

In order to obtain $E_{c-\text { (real) }}$, the digital video data of the experimental test was analysed. The camera was placed at the end of the forest structure and boulder trajectory. The boulder speed $\mathbf{v}_{u}=15,6(\mathrm{~m} / \mathrm{s})$ leaving the forest structure was determined with AviStep software. $E_{c-\text { (real) }}$ was measured taking into account both the specific gravity of the rock, assumed at $2600 \mathrm{~kg} / \mathrm{m}^{3}$, Geological Survey of Italy (1976) and the volume of the boulder. The boulder's volume has been calculated using its cylindrical shape. Its geometric measures, have been taken at the end of the test, when the boulder has arrived at the depositional zone. By applying the universal kinetic energy equation to these input data and a value of $63 \mathrm{~kJ}$ of real kinetic energy leaving the forest structure was obtained.

\section{Results}

As stated above, one aim of this study was to evaluate the energy dissipated by a specific Apennine forest structure, comparing the kinetic energy dissipation calculated by means of equations proposed in the literature with the actual energy measured in a full-scale test, in order to adapt the ADC index equation.
Table 6. Resume of data input to calculate kinetic energy dissipated with Gsteiger (1989) Eq. (4). These data are divided into two sections: ADS_1 and ADS_2, that representing respectively two forests structures crossed by boulder in real size test.

\begin{tabular}{lll}
\hline Parameter & ADS_1 & ADS_2 \\
\hline$L_{\text {tra }}(\mathrm{m})$ & 67.5 & 67.5 \\
$B(\mathrm{~m})$ & 0.68 & 0.68 \\
$U_{\text {frWood }}\left(\mathrm{J} / \mathrm{m}^{3}\right)$ & 102800 & 102800 \\
$W_{d b h m}(\mathrm{~J})$ & 1099.96 & 606.52 \\
\hline
\end{tabular}

Using the values obtained, by comparing $E_{c-\text { (simulate) }}-E_{c-(\text { real })}(122 \mathrm{~kJ}-63 \mathrm{~kJ})$ with $E_{\text {diss-(calculate) }}$ (valued at $34 \mathrm{~kJ}$ ), it emerged clearly that the kinetic energy dissipation calculated using Gsteiger's approach was slightly underestimated $(34 \mathrm{~kJ}$ compared to $59 \mathrm{~kJ})$. This suggests strongly that is not possible to apply the ADC index proposed for high forests to coppice.

In fact, coppice structures differ from those of high forest. As a number of coppice shoots grow from each stump, it is possible to assume that they occupy approximately the same position in the area, see Fig. 2. Initially, this study used as number of trees $(N)$ in its sample area $(A)$, the sum of healthy trees and the number of stumps, assuming that the boulder could strike only one sample per stump of average diameter. In doing this, the actual protection value was underestimated.

In fact, considering both the fact that a number of coppice shoots grow from each stump and the spatial distribution of these coppice shoots, it is clear that the ADC index has to be increased, with a consequent reduction in dissipated energy.

However, it should also be taken into consideration that a coppice can have a "sail" effect, increasing the interceptive surface for each stump. Therefore, the $W_{\mathrm{dbhm}}$ increases as well as the energy dissipation per impact see Fig. 3.

To improve understanding of the action of coppice structures with regard to rockfall events, it is necessary to take into consideration the average diameter of a given falling boulder. If the boulder is small, it will have more opportunity than a large boulder to pass through the coppice shoots of the same stump. This phenomenon is further amplified when boulders bounce higher, so that they cross the coppice shoots at 


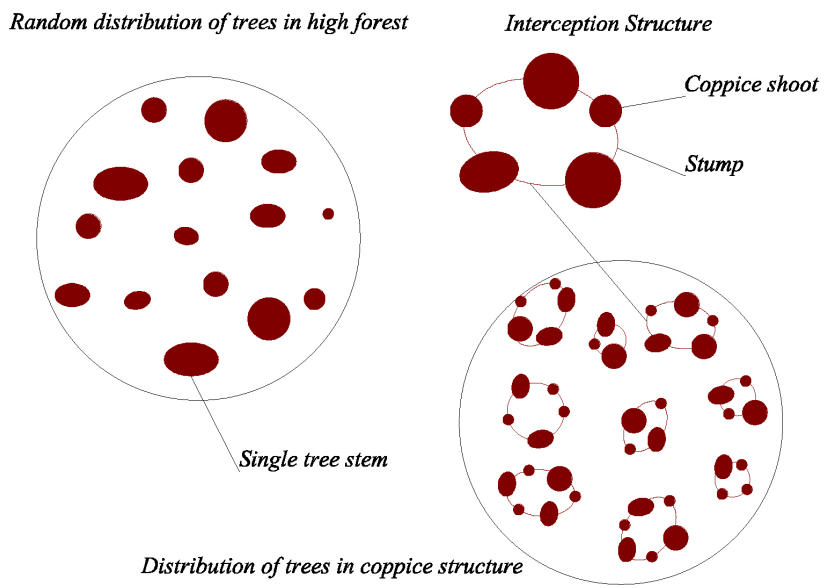

Fig. 2. Graphical representation of random distribution of trees in high forest, and difference with cluster distribution (Interception Structure) in the coppice structure.

a greater height, where the distance between trunks naturally increases see Fig. 3.

Therefore, if the average diameter of a boulder $(B)$ is smaller than the average distance between coppice shoots $(\mu \mathrm{d})$, we assume that forest structure is similar to a high forest with random distribution of trees per hectare. On the contrary, if $(B)$ is greater than $(\mu \mathrm{d})$, an "Interception Structure" in the ADC index calculations, has to be considered. Thus, if $(\bullet)(B)<(\mu \mathrm{d})$ it is more useful to use Gsteiger's ADC formula with Eq. (4), whereas $(\bullet)$ if $(B)>(\mu \mathrm{d})$ the authors propose the following Eq. (6) to calculate the ADC index:

$$
\begin{aligned}
& \mathrm{ADC}=\frac{A}{\left(N_{c}+N_{s}\right) \cdot B+N_{c} \cdot d b h_{s i}+N_{s} \cdot d b h_{m}}= \\
& =\frac{A}{\left(N_{c}+N_{s}\right) \cdot B+N_{c} \cdot\left(d b h_{m}+\overline{d b h_{\mathrm{int}}}\right)+N_{s} \cdot d b h_{m}}
\end{aligned}
$$

where the mean diameter of the stump is associated with the number of stumps $\left(N_{c}\right)$ and is defined as the mean diameter of the "Interception Structure", proposed as $\left(d b h_{s i}\right) . d b h_{s i}$ is the sum of the mean diameter at breast height $\left(d b h_{m}\right)$ plus the mean distance between the coppice shoots of the stump $\left(d b h_{\text {int }}\right)$. In this case, the $\left(d b h_{\text {int }}\right)$ value can be calculated arithmetically as the mean of distances $\left(d_{1} \div d_{n}\right)$ see Fig. 3, based on a significant sample of stumps. In this study a mean distance between coppice shoots equal to $\overline{d b h_{\text {int }}}=0.5 \mathrm{~m}$ was used.

In this work, mean $d b h_{\text {int }}$, has been obtained through the enumeration's measures of a coppice shoots sample. Changing $d b h_{\text {int }}$ value in Eq. (6) into a rank of $\pm 10 \mathrm{~cm}$, is possible to see that there are not big changes of ADC index, $\pm 0.03 \mathrm{~m}$. At the same time, it is necessary to consider that, a silvicultural treatment with the cut of one or more coppice shoots, involves a big increase of $d b h_{\text {int }}$. So, if $d b h_{\text {int }}$ is bigger than

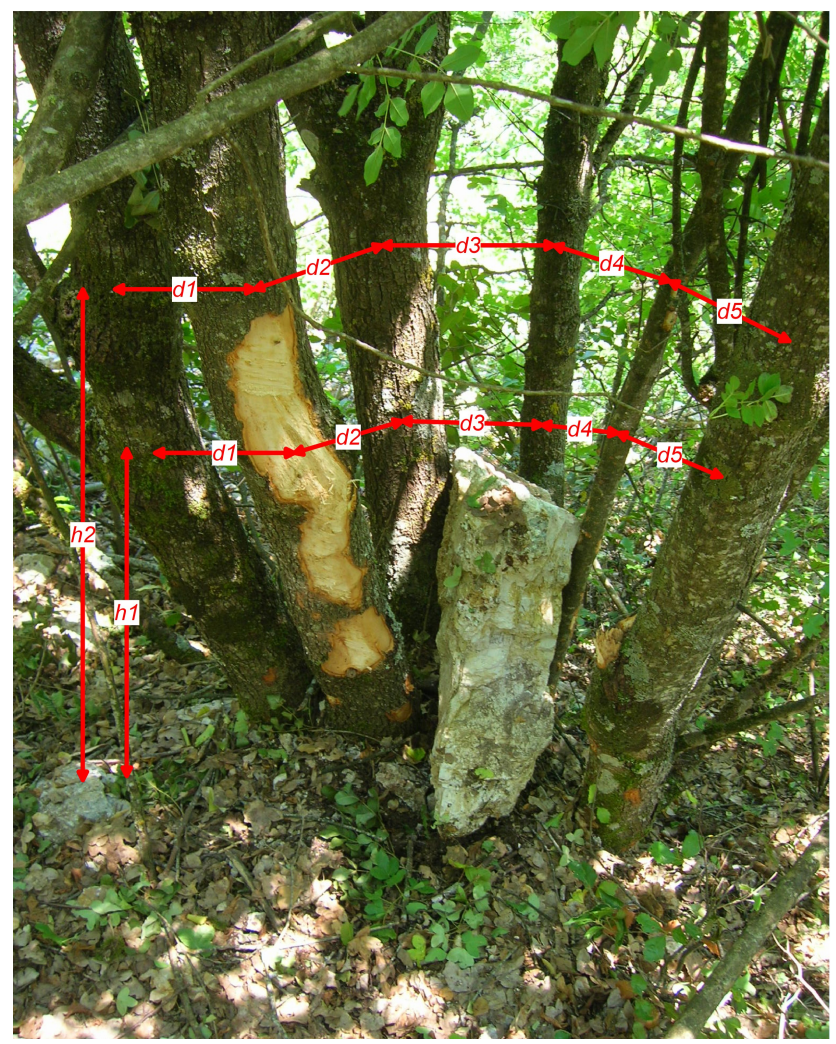

Fig. 3. Graphical representation of distances between coppice shoots in the "Interception Structure".

the boulder diameter, we should use Eq. (4) to calculate ADC index, that in this way, will have changed significantly its values.

In recalculating $E_{\text {diss-(calculate) }}$ through Eqs. (6) and (4), a resulting dissipated kinetic energy value of $53.831 \mathrm{~kJ}$ was obtained. This value is closer to the value determined by using data from the experimental site, i.e., $59 \mathrm{~kJ}$.

\section{Discussion}

\subsection{Discussion of the approach to measuring/evaluating energy absorption by coppice}

The results obtained in this study allowed a new approach to calculating the ADC index to be elaborated, requiring a knowledge of the number of trees per hectare so that what the authors term as "Interception Structures" (SI) can be considered.

The concept of the ADC is based on the assumption that plants are locally randomly distributed. However, since a coppice tends to have a more clustered distribution, this assumption is not satisfactory. For example, the trajectory of a given boulder might pass through a cluster, in which case it would be likely to hit several stems, on the other hand, its trajectory might be through a relatively empty area, in which 
Table 7. Silvicultural system in Marche region, data from Regional Forest Inventory (Sistema Informativo Forestale Regionale - SIFR 2001).

\begin{tabular}{lll}
\hline Forest structure types & Area (ha) & Area $(\%)$ \\
\hline Coppice with reserves & 87050 & 43.3 \\
Natural high forest & 28550 & 14.2 \\
Coppice with a lot of reserves & 30275 & 15.0 \\
Young forest & 13400 & 6.6 \\
Coppice with standards system & 13250 & 6.6 \\
Forest without management & 7900 & 3.9 \\
High forest (forestation) & 16775 & 8.3 \\
Coppice in conversion & 3150 & 1.5 \\
Coppice selection system & 350 & 0.1 \\
Total & 200700 & 100 \\
\hline
\end{tabular}

case it might hit none at all. Therefore the ADC index cannot be applied in the same way to coppice structures. In the ADC index, using the number of trees per hectare, a random distribution of trees in the examined area is assumed.

However, it should be borne in mind that it is difficult to compare the results obtained because the values compared are all relatively small, even when taking into consideration the statistical variability of dynamic rockfall simulations, in terms of kinetic energy, to the controlled section.

\subsection{Discussion of coppice management}

According to the Forest Inventory data System of the Marche Region (VV.AA., 2001), coppice is the most widespread (66.5\%) silvicultural system of forest, see Table 7. The majority of regional forest areas (49\%) exert a commercialprotective function, while $(11 \%)$ of these forests perform only protective roles, see Table 8 . Therefore coppice structures play a potentially major role in protection from rockfall.

A number of features of coppice influence the quantity of dissipated energy in a rockfall event: specific composition, spatial distribution and stand growth parameters. Therefore, it is necessary to obtain data on the quantity of energy dissipated by the application of various management techniques (which vary in relation to alternate phases of growth and regeneration) when applied to forests that perform protective functions.

In the Marche region, as occurs throughout the Italian Apennines, the large majority of coppices are managed as simple coppice structures, with harvest falling and reserve systems with a minimum number of 60 plants per hectare (Ministry Decree Law, 1964). This type of management, considering for example, a boulder similar to that in the experimental test, with an average reserve diameter at breast height of $20 \mathrm{~cm}$, would obtain ADC values of around $190 \mathrm{~m}$. It is generally known that a boulder reaches maximum speed, and thus, maximum kinetic energy, in about $30 \mathrm{~m}$ (Bozzolo,
Table 8. Forest function in the Marche region, data from Regional Forest Inventory (Sistema Informativo Forestale Regionale - SIFR 2001).

\begin{tabular}{lll}
\hline Forest function & Area (ha) & Area (\%) \\
\hline Commercial- protective forest & 99100 & 49.3 \\
Naturalistic & 59850 & 29.8 \\
Protective forest & 22875 & 11.4 \\
Commercial forest & 11775 & 5.8 \\
Public use & 1250 & 0.6 \\
Free growth & 5850 & 2.9 \\
Total & 200700 & 100 \\
\hline
\end{tabular}

1987). For forest structures to play a fundamental role in rockfall protection, it is necessary for the ADC index to be less than $30 \mathrm{~m}$. Therefore, the value estimated above for simple coppice structures (i.e., around $190 \mathrm{~m}$ ), can be considered comparable to the absence of any forest structure, and offers poor protection.

Among the types of management for coppices, the most pertinent to rockfall protection are those closest to high forests. For example, the coppice selection system is characterised by ideal features, even though this system is not often practiced in the region ( $0.1 \%$ of regional forest). In this system, two or more coppice shoots, having an age equal to, or a multiple of, the rotation (i.e., the time that elapses between one harvest and the following one), are always left growing on the stump. The traditionally silvicultural systems recognised that the benefit of such silvicultural systems lies in the possibility of obtaining fuel wood for the local population. This study suggests that a further benefit is a reduction in the Average Distance between Contacts and an improvement in the Structure of Interception function, which could lead to an increase in rockfall protection.

Another positive aspect of such silvicultural systems is the roughness of the ground which characterises them and the normal restitution coefficient. These parameters are improved by the effect of the stumps, which tend to be particularly large and are often above ground. However, it is quite clear that this type of management requires specialized skills in cutting, which are much more complex than those required for simple coppice management.

Other types of management which can improve rockfall protection include coppices with large reserves and coppices with a standards system. Among the types of coppice management closer to high forest, these are the most frequently used in the region, representing respectively $15.0 \%$ and $6.6 \%$ of regional forest.

Coppices with large reserves have structures similar to even-aged forests in their layers of reserves. Coppices with large reserves have the advantage of having a lower ADC than simple coppice systems, although they do not have the 
reserves of uneven-aged structures which would allow such a form of management not to increase the ADC during cutting operations.

Coppice with standards systems, instead, are characterised by the simultaneous presence of two structures: coppice and high forest. High forest can be pure or mixed, consisting of reserves with different classes of age, which are equal to, or multiples of, the rotation age. In this type of structure, two components that favour rockfall protection can be found: firstly, reserves which have a structure similar to that of high forest are preserved, where the ground is partially covered. Secondly, the presence of coppice guarantees the Structure of Interception effect.

The advantages of these types of forestry treatments can be attributed to the flexibility they give to forest management, whereby a coppice can be managed so that it produces fuelwood, without relinquishing the permanent protection guaranteed by the uneven-aged structure of the reserves.

\section{Conclusions}

The probabilistic approach to estimating the energy absorbed by a coppice based on ADC is effectively valid, but when a forest structure is not formed by single plants, as in the case of Apennine coppice, it is necessary to use a modified model.

The experimental test to assess coppice structure energy dissipation rate (selected among others performed during the initial stages of this study) suggests that the energy dissipation flow is higher than that predicted by Gsteiger's approach, Gsteiger (1989). It also indicates that corrections taking into account the actual spatial distribution of coppice shoots are needed. Consequently the proposed equation, derived from the Interception Structure concept, appears to be more suitable for estimating the ADC in the case of coppice.

According to the proposed methodology a coppice structure energy dissipation rate of $40 \mathrm{~kJ}$ along $100 \mathrm{~m}$ each has been assessed. To uphold the result a new mechanical model to describe the shots/boulder impact based on data by full scale test will be needed.

In should be borne in mind that the type of protection that forest or coppice can offer is probabilistic, unlike that offered by traditional rockfall defence systems, which is deterministic. In other words, a coppice cannot guarantee that any given boulder will be stopped. The risk of a rockfall event can be considered as equal to the probability of that event happening as a function of the vulnerability of the structures which could be damaged by it. Therefore, where the vulnerability is low, i.e. where little damage could occur to people or structures, then forest protection could be taken into consideration as a viable, ecological and cheap alternative. Where the risk is high, on the other hand, alternative protection should be used.

As regards the best practices for improving protection against rockfall by coppice structures, the results of this study suggest that the management system should be based on either the coppice selection system, or coppices with large reserves, or coppices with a standard system. In particular, the coppice selection system, once considered anachronistic, appears to be the best choice in order to provide strong protective effects against rockfall risks. Therefore, this practice should be revalued and reproposed.

Taking into account both the costs of installing traditional rockfall defence systems (steel grid, dynamics and static barriers, etc.), and their notable impact on the visual landscape, good practices of forest management could represent a suitable and effective alternative in the mitigation of rockfall hazards.

Edited by: A. Volkwein

Reviewed by: T. Lundstróm and M. Stoffel

\section{References}

Berger, F., Corominas, J., Lopez-Carreras, C., Brauner, M., Kienholz, H., and Grassl, H.: ROCKFOR Project, Rockfall - Forest Interrelation, Efficiency of the Protective Function of Mountain Forest against Rockfall, First Annual Report, 2001.

Berger, F., Corominas, J., Lopez-Carreras, C., Brauner, M., Kienholz, H., and Perry, B.: ROCKFOR Project, Rockfall-Forest Interrelation, Efficiency of the Protective Function of Mountain Forest against Rockfall, First Annual Report, 2004.

Brauner, M., Weinmeistera, W., Agnera, P., Vospernikb, S., and Hoesle, B.: Forest management decision support for evaluating forest protection effects against rockfall, Forest Ecol. Manag., 207, 75-85, 2005.

Bruschi, A.: Meccanica delle rocce. Nella pratica geologica ed ingegneristica. Ed. Flaccovio Dario, 2004.

Chauvin, C., Renaud, J. P., and Rupé, C.: Stabilité et gestion des forêts de protection, ONF Bull. Techn., 27, 37-52, 1994.

Ciancio, O. and Nocentini, N.: Il bosco ceduo. Selvicoltura Assestamento Gestione, Accademia Italiana di Scienze Forestali, 2004.

Couvreur, S.: Les forêts de protection contre les risques naturels. École Nationale du Génie Rural des Eaux et Forêts, 89 p., 1982.

Dorren, L. K. A., Berger, F., and Putters, U. S.: Real-size experiments and 3-D simulation of rockfall on forested and nonforested slopes, Nat. Hazards Earth Syst. Sci., 6, 145-153, 2006, http://www.nat-hazards-earth-syst-sci.net/6/145/2006/.

Dorren, L. K. A., Berger, F., Imeson, A. C., Maier, B., and Rey, F.: Integrity, stability and management of protection forests in the European Alps, Forest Ecol. Manag., 195, 165-176, 2004.

Dorren, L. K. A. and Berger, F.: Stem breakage of trees and energy dissipation during rockfall impacts, Tree Physiol., 26, 63$71,2005$.

Dorren, L. K. A., Berger, F., Le Hir, C., Mermin, E., and Tardif P.: Mechanisms, effects and management implications of rockfall in forests, Forest Ecol. Manag., 215, 183-195, 2005.

Dorren, L., Berger, F., Jonsson, M., Krautblatter, M., Mölk, M., Stoffel, M., and Wehrli, A.: State of the art in rockfall - forest interactions, Schweiz Z Forstwes, 158-6, 128-141, 2007.

Frehner, M., Wasser, B., and Schwitter, R.: Nachhaltigkeit und Erfolgskontrolle im Schutzwald. Wegleitung für Pflegemassnah- 
men in Wäldern mit Schutzfunktion. Bundesamt für Umwelt, Wald und Landschaft, Bern, 2005.

Geological Survey of Italy - Italian Cartographic Boby: Geological Map of Italy at the scale 1:100 000, 1976.

Gsteiger, P.: Steinschlag Wald Relief Empirische Grundlagen zur Steinschlagmodellierung. Diploma Thesis Geography, Department of Geography, University of Berne, 1989.

Hétu, B. and Gray, J. T.: Effects of environmental change on scree slope, development throughout the postglacial period in the ChicChoc Mountains in the northern Gaspé Peninsula, Québec, Geomorphology, 32, 335-355, 2000.

Hoesle, B.: Rock Fall Problems and its Protection, Course script, Department of Civil and Structural Engineering, The Hong Kong Polytechnic University, 2001.

Jahn, J.: Proceedings, Entwaldung und Steinschlag. International Congress INTERPRAEVENT, Graz, 1, 185-198, 1988.

Jones, C. L., Higgins, J. D., and Andrew, R. D.: Colorado Rockfall Simulation Program Version 4.0. Colorado Department of Transportation, 2000.

Jonsson, M. J. O.: Energy absorption of trees in a rockfall protection forest. DISS. ETH No. 17214, 2007.

Lafortune, M., Filion, L., and Hétu, B.: Dynamique d'un front forestier sur un talus d'éboulis actif en climat tempéré froid (Gaspésie, Québec), Geogr. Phys. Quat., 51 , 1-15, 1997.

Leibundgut, H.: Unsere Gebirgswä lder. Paul Haupt Verlag, Bern, Stuttgart, 1986.

Lundström, T., Jonas, T., Stöckli, V., and Ammann, W.: Anchorage of mature conifers: resistive turning moment, root-soil plate geometry and root growth orientation, Tree Physiol., 27, 12171227, 2007.

Lundström, T., Jonsson, M. J., Volkwein, A., and Stoffel, M.: Reactions and energy absorption of trees subject to rockfall: a detailed assessment using a new experimental method, Tree Physiol., 29, 345-359, 2009.
Meissl, G.: Modellierung der Reichweite von Felsstuerzen, Innsbr. Geogr. Studien, 28, Inst. für Geogr., University of Innsbruck, 1998.

Ministry Decree Law 11/11/1964: Summary of Requirements of Forest Police. 1964.

Pfeiffer, T. J.: Rockfall hazard analysis using computer simulation of rockfalls, Master of Science Thesis, Colorado School of Mines, 1989.

Pfeiffer, T. J., Higgins, J. A., Andrew, R. D., Barrett, R. K., and Beck, R. B.: Colorado Rockfall Simulation Program Version 3.0, Users Manual, Colorado Transportation Institute, 1993.

Royal Decree Law num. 3267 - 30.12.1923, Gazz. Uff., num. 117 - 17 May, 1924.

Stoffel, M, Wehrli, A., Kühne, R., Dorren, L. K. A., Perret, S., and Kienholz, H.: Assessing the protective effect of mountain forests against rockfall using a 3-D simulation model, Forest Ecol. Manag., 225, 113-122, 2006.

Stokes, A., Salin, F., Kokutse, A. D., Berthier, S., Jeannin, H., Mochan, S., Dorren, L., Kokutse, N., Ghani, M. A., and Fourcaud, T.: Mechanical resistance of different tree species to rockfall in the French Alps, Plant and Soil, 278, 107-117, 2005.

Various authors: I tipi forestali delle Marche, Monografia dell'Istituto per le Piante da Legno e L'Ambiente IPLA e Servizio Valorizzazione Terreni Agricoli e Forestali Regione Marche, 252 pp., 2001.

Wasser, B. and Frehner, M.: Minimale Pflegemassnahmen für Wälder mit Schutzfunktionen, Wegleitung. Bundesamt für Umwelt, Wald und Landschaft (BUWAL), Berne, 1996.

Zinggeler, A.: Steinschlagsimulation in Gebirgswäldern: Modellierung der relevanten Teilprozesse. Diploma Thesis, Department of Geography, University of Berne, 1989. 